\title{
Dynamic Deformation Monitoring of Bridge Structure
}

\author{
Imrich Lipták, Alojz Kopáčik, Ján Erdélyi, Peter Kyrinovič \\ Slovak University of Technology in Bratislava \\ Faculty of Civil Engineering, Department of Surveying \\ e-mail: imrich.liptak@stuba.sk, alojz.kopacik@stuba.sk,jan.erdelyi@stuba.sk,peter.kyrinovic@stuba.sk
}

\begin{abstract}
Building structures are extremely sensitive at influence of outdoor conditions. Most often these are the influence of wind, sunshine, temperature changes of the surrounding and at least the influence of the own or other loading. According to resonance of the structure with the surrounding is coming to vibration and oscillation in relative high frequency interval $(0.1 \mathrm{~Hz}-100.0 \mathrm{~Hz})$. These phenomena significantly affect the static and dynamic characteristics of structures, their safety and functionality. The paper brings example of monitoring these phenomena. The object of monitoring is the Danube Bridge Apollo in Bratislava, which main steel structure was measured by acceleration sensors with frequency up to10 Hz. The main topic of the paper is the analysis of dynamic behavior of structure using spectral analysis method. The usage of Fourier Transform is described, own frequencies and amplitudes of structure oscillation are calculated.
\end{abstract}

Keywords: accelerometer, dynamic deformation, frequency, periodogram, spectral analysis

\section{Introduction}

It is more and more necessary today to monitor the dynamic deformation of civil engineering structure, as such deformations affect their stability and safety. A dynamic deformation is generally characterized by vibrations, inclinations and other changes in a relatively short period, which are represented in a frequency range by values ranging from $0.1 \mathrm{~Hz}$ and beyond. In these cases it is important to identify not only the amplitudes of a structure's movements but also their frequencies, too.

The Department of Surveying at the SUT in Bratislava (Slovakia) has been monitoring dynamic effects on civil engineering structures of different types and dimensions for a long time. The presented paper provides examples of the measurement system of the bridge structure situated in Bratislava. Analysis of the steel structure vibrations based on the accelerometer measurement is made with $10 \mathrm{~Hz}$ sample rate, which is sufficient for determination of the significant frequencies of the structure movement. Spectral analysis is 
used to analyzing the frequency spectrum of the structure deformation. The spectral density estimation of the measured time series is made by Fast Fourier transformation.

\section{The Apollo Bridge in Bratislava}

The Apollo Bridge is one of five bridges in Bratislava that cross the Danube (Fig. 1). These bridges are part of the most important transportation corridors in Bratislava. The traffic load, changes in the water level of the river Danube, and many other factors affect the basic functioning and safety of the bridge structure.
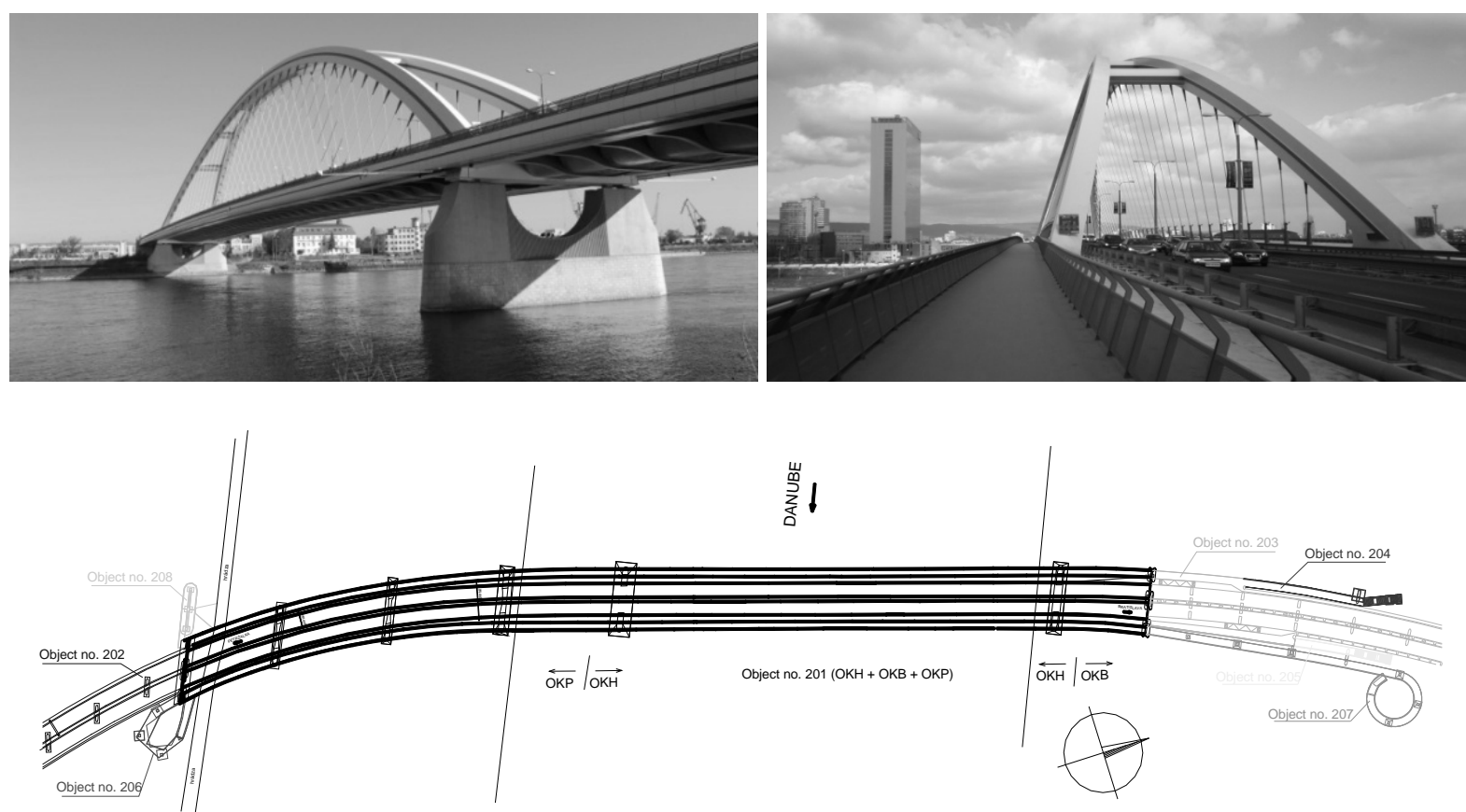

Figure 1: The Apollo Bridge in Bratislava

The bridge structure consists of eight parts - a steel structure with a length of $517.5 \mathrm{~m}$, the Petržalka concrete approach viaduct with a length of $236.0 \mathrm{~m}$, the Bratislava concrete approach viaduct with a length of $195.0 \mathrm{~m}$, and five additional parts - three staircases and two cycling bridges. The main part of the bridge is an arched steel structure with a span length of $231.0 \mathrm{~m}$ and an arch height of $36.0 \mathrm{~m} \mathrm{[1].}$

The main part of the bridge consists of two steel beams with an orthotropic bridge floor (the deck). The beams are suspended on two inclined steel arches in the center. This part consists of six expansion fields with spans that are $52.5 \mathrm{~m}, 2 \times 61.0 \mathrm{~m}, 63.0 \mathrm{~m}, 231.0 \mathrm{~m}$ and $49.0 \mathrm{~m}$ long. The top of the arch is $36.0 \mathrm{~m}$ high over the bridge deck. The pillar bases were built by injection and micro pilots. One of the pillars is positioned in the river. The main bridge structure was assembled on the river bank and then rotated and turned across the river from its construction site into its final position over the pillars [2 \& 3]. 


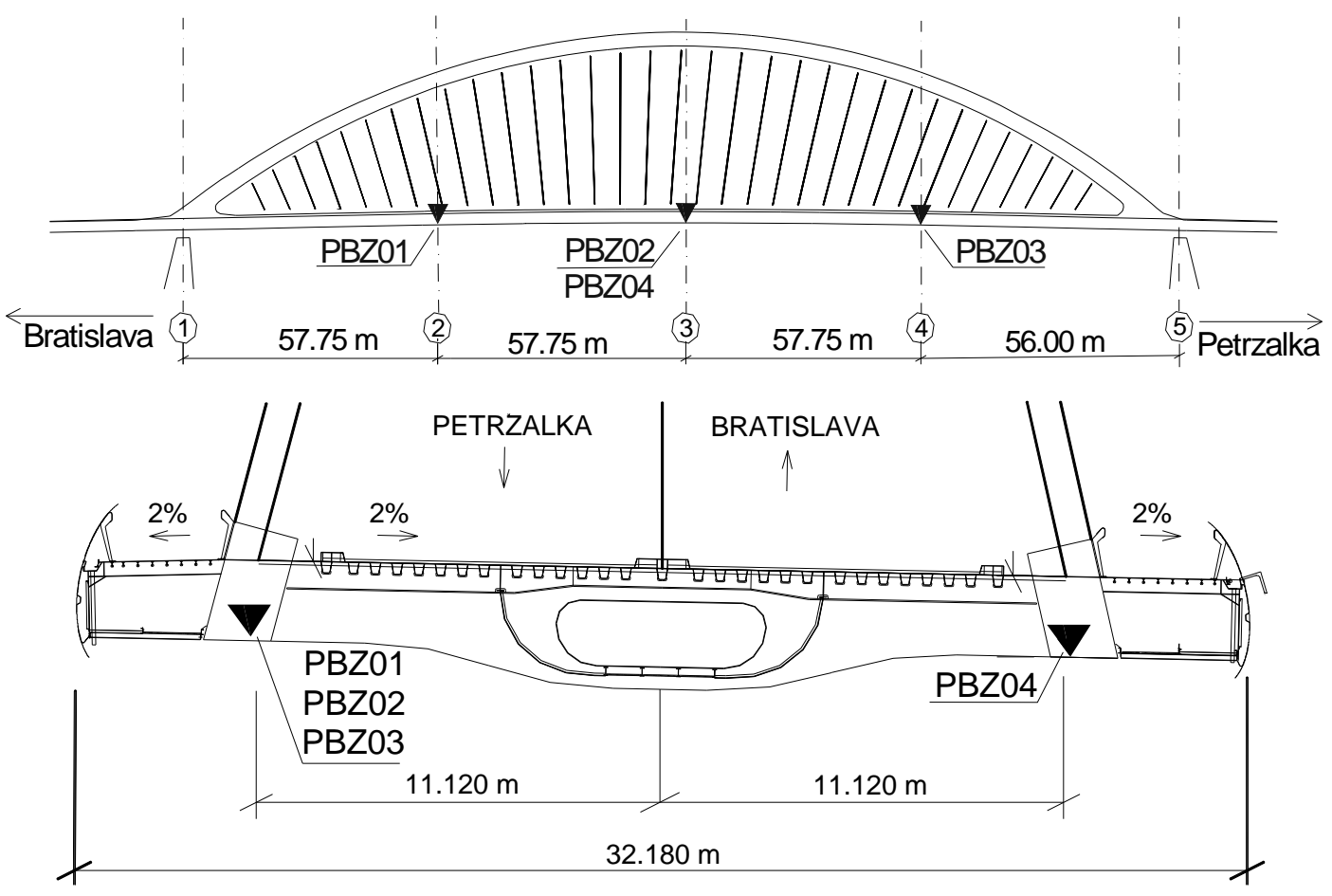

Figure 2: Locations of the accelerometers

The measurement system consisted of four 1D HBM B12/200 accelerometers manufactured by Hottinger Baldwin Measurements and was installed on the bridge deck (Fig. 2). These inductive sensors have an operating frequency of up to $200 \mathrm{~Hz}$ and a measuring range of up to $200 \mathrm{~m} . \mathrm{s}^{-2}$. The accuracy of the sensors is defined by a relative error of up to $\pm 2 \%$ [4]. The measured signal is digitized by a Spider $8 \mathrm{~A} / \mathrm{D}$ transducer and saved to a computer $[2,3,5]$.
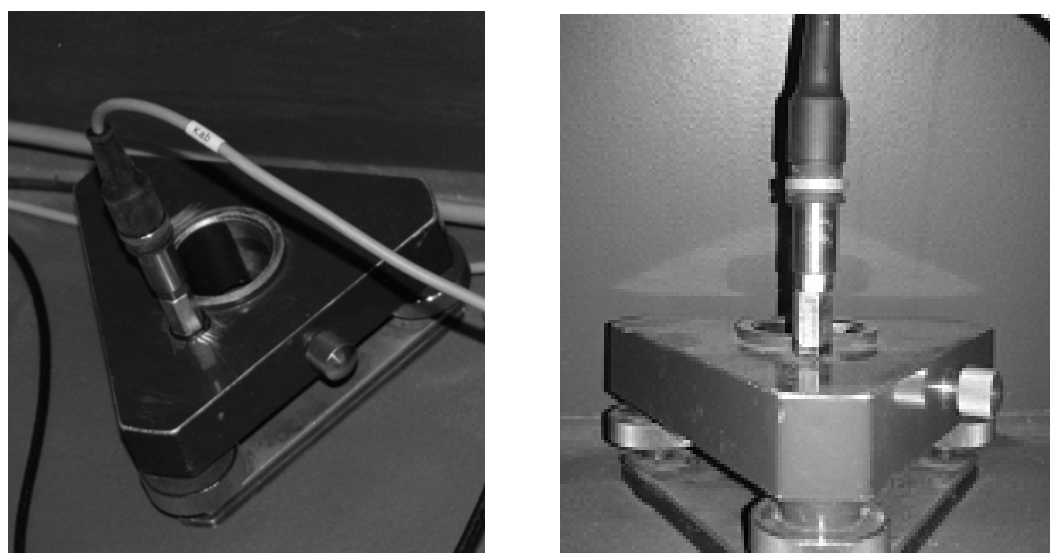

Figure 3: Accelerometer HBM B12/200

The HBM B12/200 accelerometers are situated on the left side of the bridge deck in each quarter of the length of the main bridge field (points PBZ01 to PBZ03), and the fourth 
accelerometer is situated on the right side in the center of the main bridge field (point PBZ04). The measurement axis of all the accelerometers is vertical (Fig. 3).

\section{Processing of the data}

In the case of the dynamic loading of structures, it is also desirable to describe their deformations, which are parallel to the trajectory on a frequency spectrum. Generally, the structure's own frequency or the frequency of the forced vibration of the structure is being calculated. Estimation of these characteristics can be provided by spectral analysis methods, which enable to determine spectral density of time series. Figure 4 describes steps of accelerometer data processing.

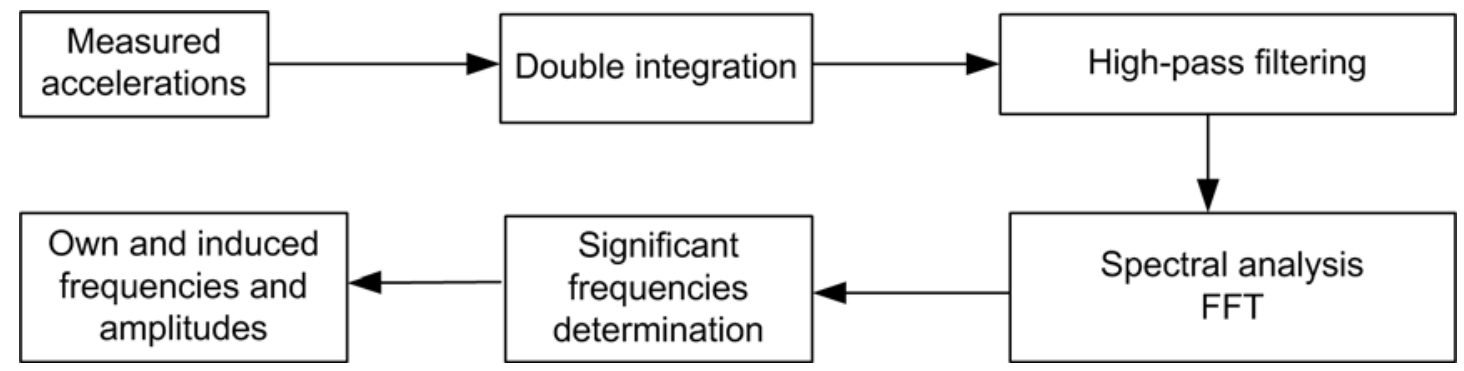

Figure 4: Steps of processing of the data

The accelerometers provide measurements and data registration at a $10 \mathrm{~Hz}$ sample rate. Measured accelerations are transformed into velocities and relative displacements by double integration of acceleration data between two next epochs of measurement, according to general formula

$$
s(t)=s_{0}+v_{0} \times t+\int_{0}^{t}\left(\int_{0}^{t} a(t) d t\right) d t,
$$

where $s(t)$ is the displacement at time $t, a(t)$ is the acceleration at time $t, s_{o}$ is the initial position, and $v_{o}$ is the initial velocity [6].

Accelerometer drift is eliminated by high-pass filter of low frequencies in time series. In this case moving average filter has been applied. Frequency characteristics are determined by spectral analysis methods. Generally, the Fourier Transformation is used. Describes a signal by its harmonic functions and can be used for transforming a signal from a time domain to a frequency domain [7]. Generally is defined as

$$
F(\omega)=\frac{1}{2 \pi} \int_{-\infty}^{\infty} f(t) e^{-i \omega t} d t .
$$

In practical use, a power spectral density is estimated by Fast Fourier transformation (FFT) algorithm with application of Hamming spectral window function. FFT is algorithm for Discrete Fourier transformation (DFT) solving, which is based on transformation of discrete 
measurements from time domain to frequency domain [8]. Generally, DFT is described by mathematic formula

$$
X_{k}=\sum_{j=0}^{N-1} y_{j} w(j) \exp \left(\frac{2 \pi i j k}{N}\right),
$$

where $y$ is measured data and the $w$ is a spectral window function [ $8 \& 9$ ]. For determining the significant frequencies from the discrete frequency spectrum, the Fisher's asymmetric statistical test of periodicity was used [7 \& 10].

\section{Analysis of the data}

The spectral density estimation was done using data sets with 18,000 epochs, which represent a time range of 30 minutes. The maximum deformation ranges up to $1 \mathrm{~mm}$. The greatest effect on the dynamic deformation of the structure is caused by both - transportation (traffic) and weather loading. As an illustration, intervals with and without a traffic load were chosen from measurements realized at points PBZ01 (Figs. 5 and 6) and PBZ02 (Figs. 7 and 8). In Tables 1, 2, 3 and 4, significant frequencies determined by Fisher's asymmetric statistical test of periodicity are shown.
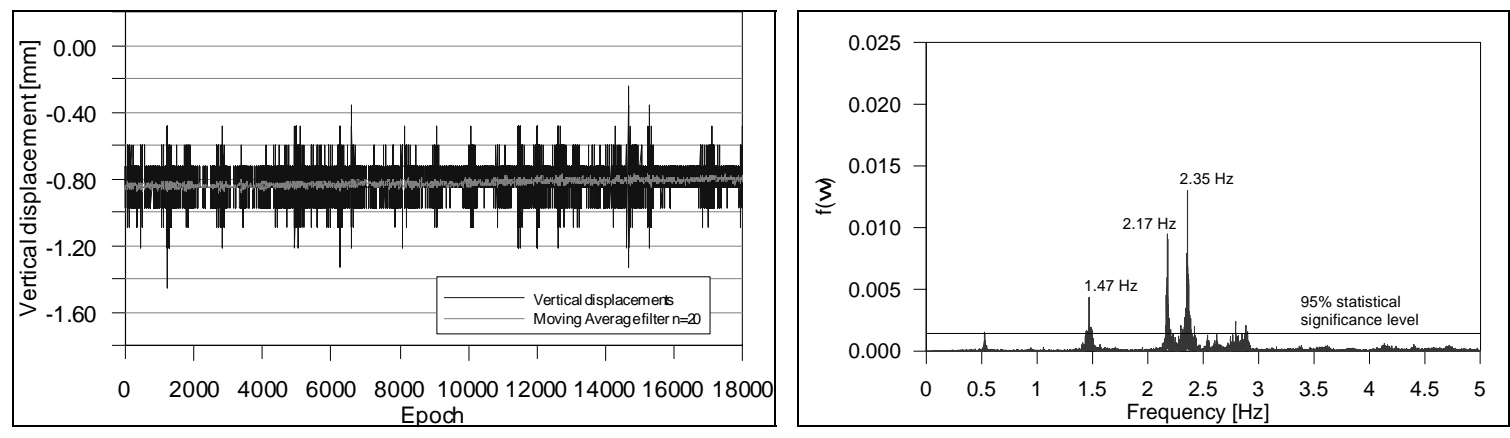

Figure 5: Displacements (left) and periodogram (right) at the PBZ01 from 04:30 p.m. to 05:00 p.m. - with traffic

Table 1: Dominant frequencies at the PBZ01 from 04:30 p.m. to 05:00 p.m. - with traffic

\begin{tabular}{|c|c|c|c|c|}
\hline $\begin{array}{c}\text { Number of } \\
\text { significant } \\
\text { frequencies }\end{array}$ & $\begin{array}{c}\text { Test statistic } \\
\hat{W}\end{array}$ & $\begin{array}{c}\text { Critical } \\
\text { value } \\
F_{\text {crit }}\end{array}$ & $\begin{array}{c}\text { Frequency } \\
{[\mathrm{Hz}]}\end{array}$ & $\begin{array}{c}\text { Period } \\
{[\mathrm{s}]}\end{array}$ \\
\hline & $4.343 .10^{-3}$ & $7.759 .10^{-4}$ & 1.47 & 0.68 \\
154 & $9.469 .10^{-3}$ & $7.749 .10^{-4}$ & 2.17 & 0.46 \\
& $1.209 .10^{-2}$ & $7.748 .10^{-4}$ & 2.35 & 0.42 \\
\hline
\end{tabular}



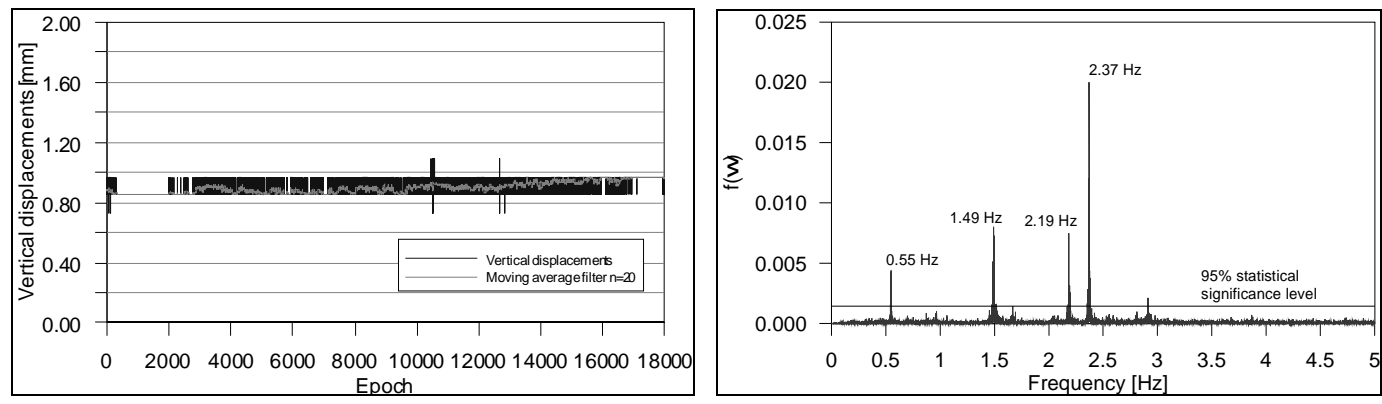

Figure 6: Displacements (left) and periodogram (right) at the PBZ01 from 00:00 a.m. to 00:30 a.m. - without traffic

Table 2: Dominant frequencies at the PBZ01 from 00:00 p.m. to 00:30 p.m. - without traffic

\begin{tabular}{|c|c|c|c|c|}
\hline $\begin{array}{c}\text { Number of } \\
\text { significant } \\
\text { frequencies }\end{array}$ & $\begin{array}{c}\text { Test statistic } \\
\hat{W}\end{array}$ & $\begin{array}{c}\text { Critical } \\
\text { value } \\
F_{\text {crit }}\end{array}$ & $\begin{array}{c}\text { Frequency } \\
{[\mathrm{Hz}]}\end{array}$ & $\begin{array}{c}\text { Period } \\
{[\mathrm{s}]}\end{array}$ \\
\hline & $2.325 .10^{-3}$ & $7.758 .10^{-3}$ & 0.55 & 1.82 \\
& $4.398 .10^{-3}$ & $7.752 .10^{-3}$ & 1.49 & 0.67 \\
& $4.135 .10^{-3}$ & $7.753 .10^{-3}$ & 2.19 & 0.46 \\
& $1.096 .10^{-2}$ & $7.748 .10^{-3}$ & 2.37 & 0.42 \\
\hline
\end{tabular}
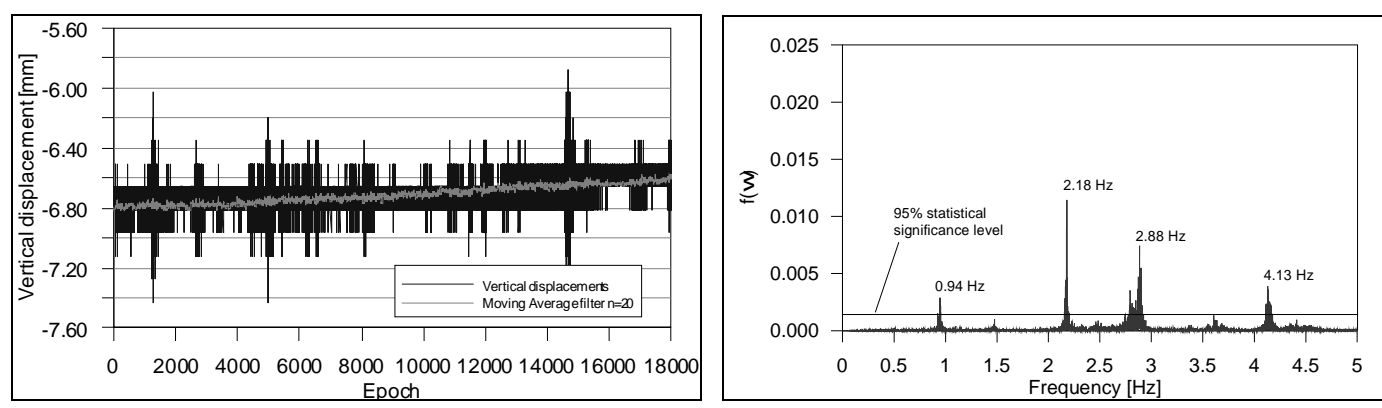

Figure 7: Displacements (left) and periodogram (right) at the PBZ02 from 04:30 p.m. to 05:00 p.m. - with traffic

Table 3: Dominant frequencies at the PBZ02 from 04:30 p.m. to 05:00 p.m. - with traffic

\begin{tabular}{|c|c|c|c|c|}
\hline $\begin{array}{c}\text { Number of } \\
\text { significant } \\
\text { frequencies }\end{array}$ & $\begin{array}{c}\text { Test statistic } \\
\hat{W}\end{array}$ & $\begin{array}{c}\text { Critical } \\
\text { value } \\
F_{\text {crit }}\end{array}$ & $\begin{array}{c}\text { Frequency } \\
{[\mathrm{Hz}]}\end{array}$ & $\begin{array}{c}\text { Period } \\
{[\mathrm{s}]}\end{array}$ \\
\hline \multirow{3}{*}{173} & $1.576 .10^{-3}$ & $7.766 .10^{-4}$ & 0.94 & 1.06 \\
& $6.237 .10^{-3}$ & $7.748 .10^{-4}$ & 2.18 & 0.46 \\
& $4.052 .10^{-3}$ & $7.750 .10^{-4}$ & 2.88 & 0.35 \\
& $2.116 .10^{-3}$ & $7.755 .10^{-4}$ & 4.13 & 0.24 \\
\hline
\end{tabular}



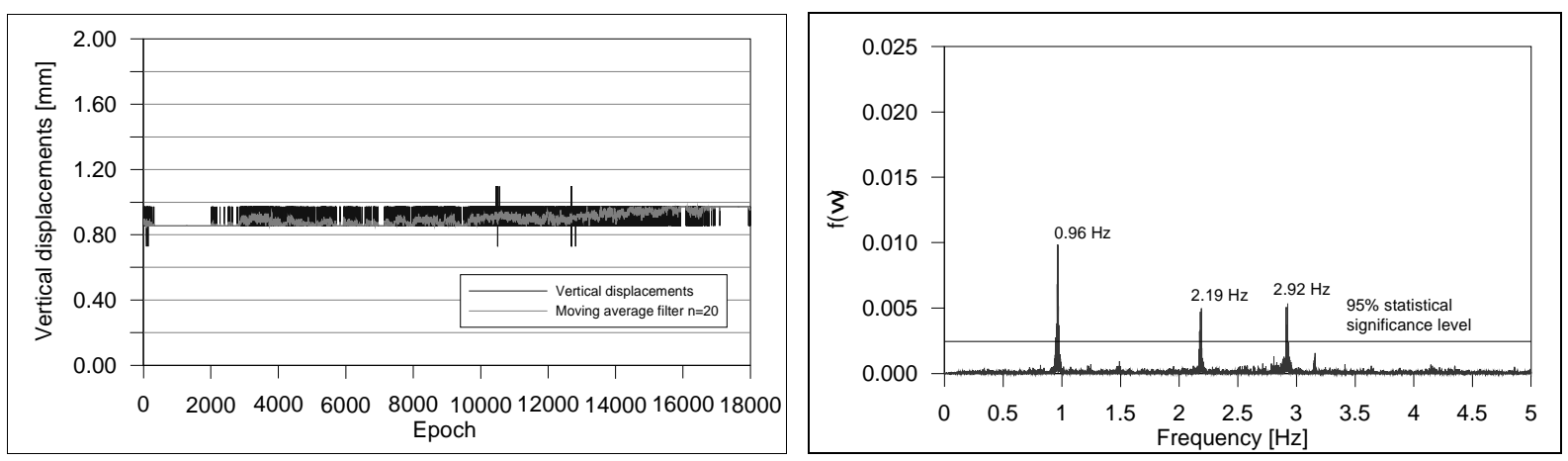

Figure 8: Displacements (left) and periodogram (right) at the PBZ02 from 00:00 a.m. to 00:30 a.m. - without traffic

Table 4: Dominant frequencies at the PBZ02 from 0:00 a.m. to 0:30 a.m. - without traffic load

\begin{tabular}{|c|c|c|c|c|}
\hline $\begin{array}{c}\text { Number of } \\
\text { significant } \\
\text { frequencies }\end{array}$ & $\begin{array}{c}\text { Test statistic } \\
\hat{W}\end{array}$ & $\begin{array}{c}\text { Critical } \\
\text { value } \\
F_{\text {crit }}\end{array}$ & $\begin{array}{c}\text { Frequency } \\
{[\mathrm{Hz}]}\end{array}$ & $\begin{array}{c}\text { Period } \\
{[\mathrm{s}]}\end{array}$ \\
\hline \multirow{3}{*}{240} & $5.292 .10^{-3}$ & $7.748 .10^{-4}$ & 0.96 & 1.04 \\
& $2.674 .10^{-3}$ & $7.748 .10^{-4}$ & 2.19 & 0.46 \\
& $2.876 .10^{-3}$ & $7.751 .10^{-4}$ & 2.92 & 0.34 \\
\hline
\end{tabular}

The data in Figures 5 and 6 are measured at point PBZ01. At both time intervals there are dominant frequencies at levels of around $1.48 \mathrm{~Hz}, 2.18 \mathrm{~Hz}$ and $2.36 \mathrm{~Hz}$. In the time series registered without any traffic loading, the next dominant frequency occurs at a level of 0.55 Hz. In both time series frequencies around the level of $2.80 \mathrm{~Hz}$ are presented, but these frequencies are at the threshold of the level of significance. The distribution of significant frequencies around the dominant frequencies is inside a range of up to $0.04 \mathrm{~Hz}$. The data in Figures 7 and 8 are measured at the central point (the midpoint of PBZ02) of the structure. In both time series three dominant frequencies are presented at levels of around $0.95 \mathrm{~Hz}, 2.18 \mathrm{~Hz}$ and $2.90 \mathrm{~Hz}$, which belong to the spectrum of the forced frequencies of the structure. In the data set without any traffic loading, the next significant frequency at a level of $4.13 \mathrm{~Hz}$ is presented. Significant frequencies are distributed around the dominant frequencies inside a range of up to $0.1 \mathrm{~Hz}$ (Figs.7 and 8). This may be caused by the position of the sensor in the center of the bridge deck. The relative accuracy of the estimated spectral densities is up to 0.4 $\%$. The estimated amplitudes of the dominant frequencies at both points are up to $1.10^{-2} \mathrm{~mm}$. The frequencies which occurred in the time series from 4:30 p.m. to 5:00 p.m. represent the permanent influence of the traffic load on the structure. The time series from the afternoon data sets are characterized by higher oscillations with maximal deflections of up to $1 \mathrm{~mm}$ (Figs. 5 and 7). In the data sets from 0:00 a.m. to 0:30 a.m. the maximal oscillations are at a range of up to $0.2 \mathrm{~mm}$ (Figs. 6 and 8 ). 


\section{Conclusion}

This paper presents the results of the monitoring of the dynamic deformations of a bridge structure (the Apollo Bridge). The geometry of the measured structure, deformation characteristics and operating restrictions affect the realization of the monitoring. The oscillation frequencies of the structures were determined by the FFT procedure. The dynamic deformation represented by the oscillation of the Apollo bridge deck, with a frequency from $0.5 \mathrm{~Hz}$ to $4.2 \mathrm{~Hz}$, is mostly induced by changes in the traffic load. Presented measurement system is a part of automated measurement system for long-term geodetic monitoring of the Apollo bridge structure [2, 3, 5]. Results present important information about behaving of monitored structures in real time induced by operational load and atmospheric conditions.

\section{References}

[1] Beňo, J. \& Szabó. R. (2006). The Apollo Bridge over Danube in Bratislava by view of general contractor. In $14^{\text {th }}$. Slovak geodetic days. (147-160). Bratislava: Chamber of surveyors and cartographers.

[2] Kopáčik, A., Kyrinovič, P., Lipták, I. \& Erdélyi, J. (2011). Automated monitoring of the Danube bridge Apollo in Bratislava. (p. 11). In FIG Working Week 2011 : 6th National congress of ONIGT. Bridging the gap between cultures. Marrakech. Morocco. 18.-22.5.2011.

[3] Kopáčik, A. \& Lipták, I. (2011). Frequency Analysis of Structure Deformation. In Joint international symposium on deformation monitoring. Proceedings. Hong Kong, China: 2. 4.11.2011.

[4] Hottinger Baldwin Messtechnik. (2000). Acceleration transducer B12. 2012-04-15, http://www.hbm.com.pl/arch/a0764.pdf.

[5] Kopáčik, A., Kyrinovič, P., Erdélyi, J., \& Lipták, I. (2011). New Trends of Automated Bridge Monitoring. Reports on Geodesy. No. 1 (90). 173-181.

[6] Hwang, J., Yun H., Park, S., H., Lee, L. \& Hong, S. (2012). Optimal Methods of RTK -GPS/ Accelerometer Integration to Monitor the Displacement of Structures. [Electronic version]. Sensors. Volume (12), 1014-1034. 2012-02-27, MDPI. DOI 10.3390/s120101014.

[7] Cipra, T. (1986). Time series analysis with applications in economics. Prague: SNTL/ALFA, $246 \mathrm{pp}$.

[8] Cooley, J., W. \& Tukey, J., W. (1965). An algorithm for the machine calculation of complex Fourier series. In Mathematic Computation. No. 19 (90). 297-301.

[9] Kuo, S. \& Lee, B. (2001). Real-time digital signal processing. John Wiley \& Sons Ltd. 496 p.

[10] Siegel, A., F. (1980). Testing for periodicity in a time series. In Journal of the American Statistical Association. No. 75. 345-348. 